\title{
BEYOND BIGNESS. SOBRE LAS IMPLICACIONES CRÍTICAS DE UNA \\ LECTURA FORMAL DE LA OBRA DE REM KOOLHAAS (1987-1993)
}

BEYOND BIGNESS. ON THE CRITICAL IMPLICATIONS OF A FORMAL READING OF THE

WORK OF REM KOOLHAAS (1987-1993)

Francisco González de Canales RESUMEN En la historia de la arquitectura más reciente, la nocí́n de bigness (grandezą, que tiene la cualidad de grande), apa-
rece íntimamente lisadad al lanzzamiento internacional de la carrera de Rem Koolhaas a principios de los 90 . En titempos de la autonomia discipininar y el regionalismo critico bigness parecia traer libertad, frescura y desprejulicio, haciendo que una generación más joven de arquitectos s tééricos proclamara la nueva hegemonía de Koolhaas como el triunfo de una nueva posición "post-critica", demostrar este texto a través de una lectura formal de la obra de Kool haas es lo contrario: es deciri, que los principios fundtamentaes que motivan su obra son principalmente criticos respecto a la producción espacial y las condiciones sociales y culturales en las que se generan, y que son estos los que inician una busqueda formal continua en su obra. Centranndose en un periodo particular de su carrera entre 1987 y 1993, el ensayo propondrá la hipótesis de que el desplazamiento de Koolhaas, desde su interés por revisar retóricamente el lenguaje de las vanguardias a la recuperación del concepto de bigness y otros mecanismos de proyecto respecto a la normatividad social y cultural en la que toda producción espacial se inscribe.

PALABRAS CLAVE Koolhaas; bigness; mat-building; loop; post-critica: forma

SUMMARY In the recent history of architecture the notion of bigness has be closely related to the launching of Rem Koolhaas career in the early 1990s. In the times of disciplinary autonomy and critical regionalism Koolhaas' bigness meant freshness, liberation and a certain sense of freedom from prejudices. As a consequence, a younger generation of architects and theorists has claimed architect. This text, however, tries to prove the opposite through a formal reading of Koolhaas' work; this is, that the fundamental principles which drive Koolhaas' work are mainly critical to the existing spatilal production and the social and cultural conditions in which this is generated as a principle for his endless formal investigation. Focusing on Koolhaas' production between 1987 and an interest in revisiting the languase of the architectural avant gardes to the recovery of the concept of hisness and other design tools form the late 1980 s on, is based on a continuous search for the liberation of users' action with respect to the normative social

KEY WORDS Koolhass; bigness; mat-building; ; lop;; post-critical; form

Persona de contacto / Corresponding author: currocanales@us.es. Escuela Técnica Superior de Arquitectura. Universidad de Sevilla

H ablar de una arquitectura critica implica necesanamente disolver la separación entre la práctica de la arquitectura como profesion y la critica de la arquilectura oomo escritura, es decir, entre obra y pensamiento, entendiendo además que la producción de arquitectura puede ser en sí resistente y en oposición a la cultura dominante. Dirimir sobre la existencia de esta actitud en Koolhaas, $y$ de una relación fluida entre pensamiento y Kobra constrilla, va a ser sin embargo upa compleja. En pinmer lugar, la ambiguedad de muchos de sus textos, de sus declaraciones e incluso el modo en que presenta sus obras crearía una primera dificullad. pesar de que Kool has ha prolagonizado un periodo particular de la culura arquitectonica como uno de sus más polemicos comentaristas, sus obsonaciones han sido a menudo engañosas en relación a sus propios proyectos oscureciendo más que aclarando los principios reales so.

Por otro lado, encontrar una posición critica en Koolhaas es tambien dificil en cuanto que esta no parece se ácilmente asimilable a cualquiera de los ejemplos más conocidos para una arquilectura cilica en los discursos europeos y americanos de los 70y80, desde Tafuriy Ross a Eisenman y Frampton². En general, Koolhaas no parece arquitectónica (las del capital o las de la banalización de cultura, por e (mplo), sino que parece estar en connivencia con ellas, aprovechándose de su potencial para fluir cabalgar con ellas. Como afirma una de sus más tamosas expresiones, la aquilectura "se relaciona con hs inezas de la Groszstaul como un suritista lo hace con las olas". Consecuentemente, esta ruptura con las formas canónicas

1. Textos muy conociodos de Koolhaas como Generic City o Junk Space son polémicos precisamente por esa ambigü̈edad. Tres textos que contienen tres mo-

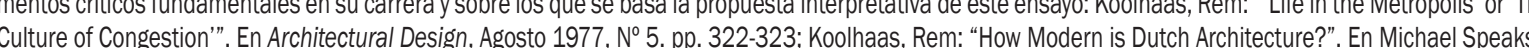
Gerard. Hadders (Eds.): Mart Stam's Trousers. Rotterdam: 110 Publishers, 1990. pp. 159-167 y Koolhaas, Rem: "Found in Translation". En Archis. 2006, № 5 , pp.120-127, este último fundamental para entender con más profundildad la posicion crritica de Koolhaas respecto a Generic City y Junk Space. En "Atlanta signific que deras New York: The Monacelli Press, 1994. pp. 832-859.

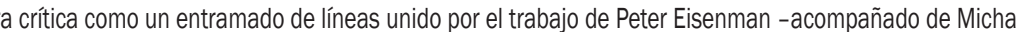
Hays, las prácticas artísticas minimalistas - sobbre todo en las palabras de Rosalind Krauss, el trabajo de Manfredo Tafurir y la resistencia a la cultura de con

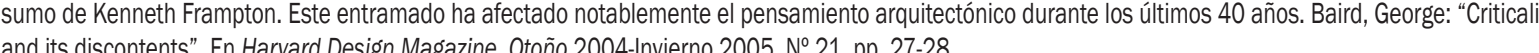
and its discontents. En Hanch Design Magazine. Otono 2004-invierno 2005, № 21. pp. 27-28.

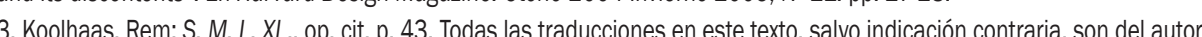


en las que se ha expresado la arquitectura crítica ha sido mpliamente considerada como una ruptura con el proyecto crítico en sí mismo. Es más, siguiendo la lectura de algunos de sus textos más conocidos, como Generic Chy o Junkspace, existe la creencia generallzada de que los proýa os de Koll a c constryér en si mismos una

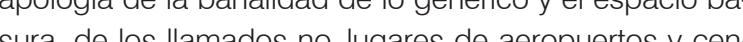
sura, de los lals: os no-lugré de aropuesos y cen-

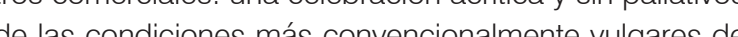
la ciuda y la arquitectura contemporáneas4. Siguiendo esta interpretación la mayoría de los argumentos proce dentes de generaciones de arquectos más jóves definir la posición de la arquitectura de Koolhaes insisten n esta actitud post- rítica, conscientes de que con Koolhaes se rompe con una consolidada tradición de arquihas se rítios de personalidades tan variadas como Aldo Rossi, Peler Eisenman, Rafel Moneo ólvaro Siza Aldo Rossi, Peter Eisenman, Ratael

Todas estas reflexiones olvidan sin embargo aspectos

Trmentales de la obra de Koolhars que se remontan a sus años de formación no sólo en Nueva York sino también en la Architectural Association (AA) de Londres. Es la intención de este ensayo probar que detrás de la idea de bigness y otros conceptos del periodo no sólo existe una obvia intención de autopromoción del arquitecto a través del marketing y la polémica, sino también una particu-

análisis formal de su arquitectura. Desde esta perspectiva que parte de sus intereses formativos, lo que movería a la rquitectura de Koolhaas sería la búsqueda de una liberad de acción de los individuos en el espacio, aspiración propia del ambiente de la AA de los años 60 y 70 , y que se promovía a través de agitadores como Cedric Price intoxicación de pensadores del $68^{6}$. La posición de quito holandés partiría por tanto de una critca del qué éste produce en la libertad de accín del individuo y en la que se formó su generación en los 60-70 en su lucha comín contra el legado del funcionalismo y sus consecuencias es decir de su postulado de que la acción en cualquier espacio está estrictamente proderminada por el programa para el cual este espacio fue diseñan. E este sentido, y dento de este mismo ambiente on la AA, no habŕa que menospreciar tampoco bimportancia que tuvo en los primeros años de Koolhas la asimibcín de conceptos traídos por Bernard Tschumi como el de eveno, en cunanto a acción libre no pre-programada, aunque las maneras de promover esta acción libre sean muy diferentes en ambos ${ }^{8}$ Pero lo más particular en Koolhaas es que como fiel seguidor también de O.M. Ungers, esta crítica que busca la libre acción del individuo se hace sin renunciar a la forma arquitectónica en sí misma o mejor dicho, desde la propia forma arquitectónica rechazando aś la disolución formal de Cedric Price y sus seguido-

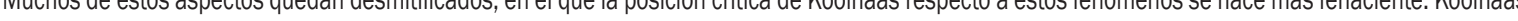
Rem: "Found in Translation". En Archis. 2006, № 2. pp. 120-12 .

5. Me refiero a autores y textos como Somol, Robert; Whiting, Sarah: "Notes on the Doppleer Effect and Other Moods of Modernism". En Perspecta. 2002, " ${ }^{\circ} 33$ p. 72-77; Speaks, Michael: "Design Intelligence and the New Economy'. En Architectural Record. Enero 2002. pp. 70-72; y Allen, Stan: "Stocktaking 2004

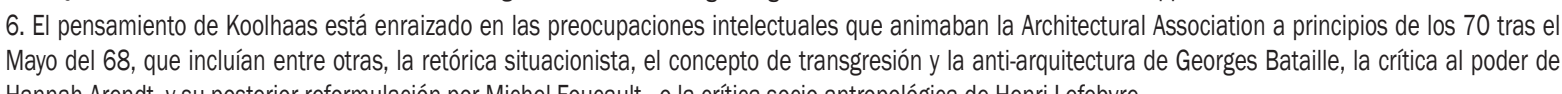

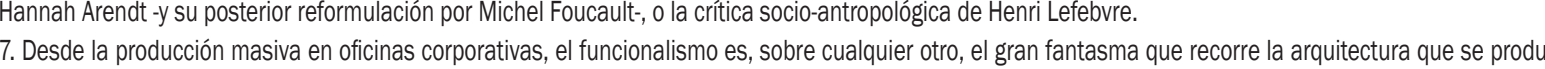

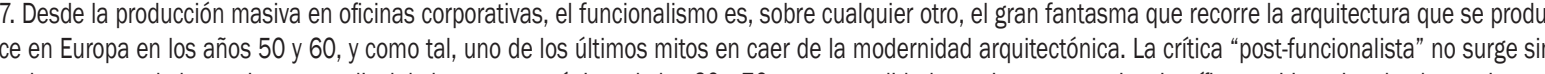
embargo tanto de la arquitectura radical de los grupos utópicicos de los 60 y 70 , que en realidad mantienen este mito cientifico-positivo, sino desde arquitecto

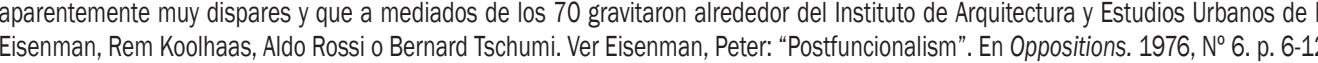

8. Tschumi fue una importante presencia para Koolhaas tanto en New York como en Londres. Para entender la noción de evento como disyunción entre espacio, programa y acción ver Tschumi, Bernard: "Space and Events". En Architecture and Disjunction. Cambridge, MA: MIT Press, 1994. pp. 140-152.

9. Moneo, Rafael: "Rem Koolhaaa". En Inquietud térica y estrategia proyectual en la obra de 8 arquitectos contemporáneos., Barcelona: Actar, 2004. pp. 308

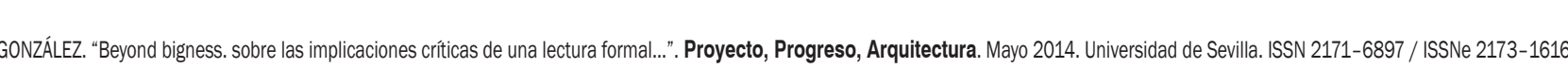

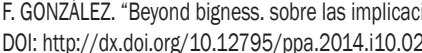
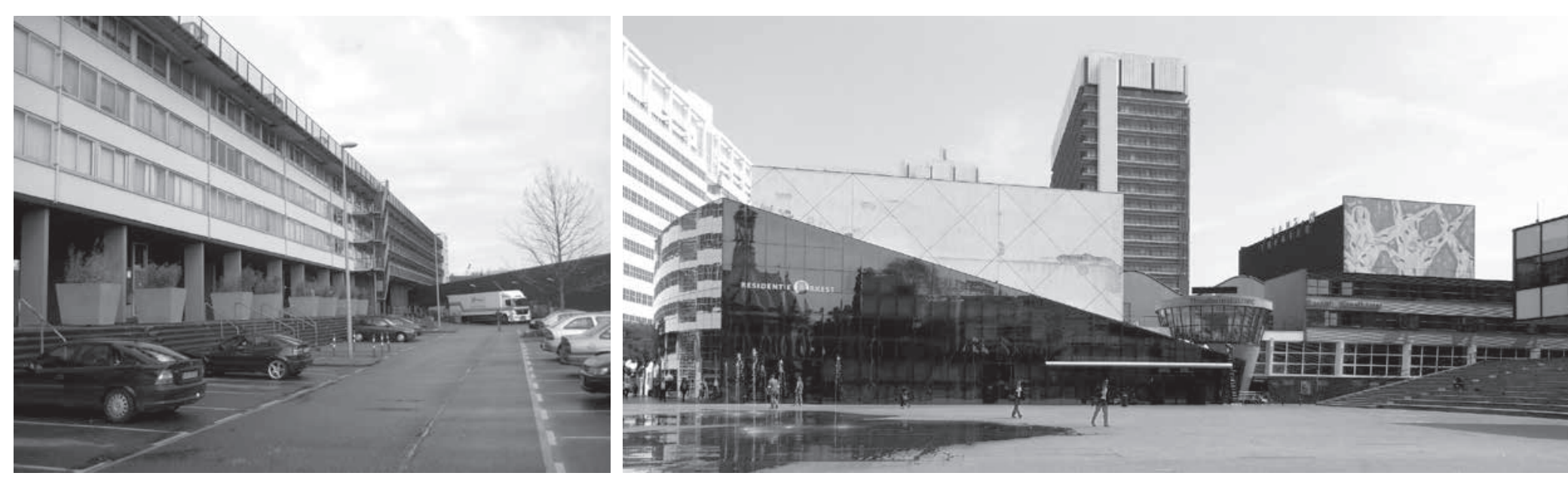

de Koolhaas: / producción de la forma arquitectónica sin coaccionar la producción de la forma arquitectónica sin coaccionar la libertad de expresión del individuo, entendiendo que esta
libertad no es algo dado, sino que está reprimida por las condiciones actuales de producción de la ciudad y la arquitectura

BIGNESS

Precedentes: Holanda 1987

En 1987 Rem Koolhaas fue invitado como profesor a la Escuela de Arquitectura de la Universidad Técnica de Dert. Historicamente enfocada hacia la profesión y si Escuela de Deff toń por entonces como práctica nabrEscuela de Dart tos por entonces como praclica habianda con el obieto de acercar academia y trabaio proional. Curiosamente, este pefil más convencinamprofesional parece encar perfectamente con 10 que era Office of Metropolitan Architecture (OMA) de entonces En aquellos años OMA estaba terminando dos proyectos nacios émsterdam (1981-1988 figura 1) y el Teatro de lan

yoría de sus proyectos y concursos desde mediade los 80 estaban también situados en el país ${ }^{\circ}$. En particular, el IJ-Plein y el Teatro de la Danza no sólo quese abrir camino profesionas de una oficina que se quiere abrir camino profesionalmente en Holanda, y que asume con mayor o menor soltura las convenciones más propios de la época (con los tipicos guinos linguristicos y las cilas retónicas postmodernas), sino que representa lanicin una ong York y que todavía estabas de Exodus y Dellious como (1985) Alejedos ya de los intereses de $M$ de La Haya profesado en su primera ́́poca estos proyectos se en-

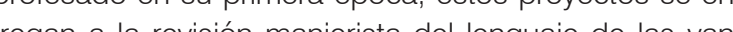
guardies dentro de una visión pragmática, aunque también lúdica, del ejercicio de la profesión ${ }^{11}$

to Koolhaas por Delf, en l reencuentro con la universidad y los estudintes, a de repente hizo surgir una feroz e inesperada autocritca sobre esta manera de hacer arquitectura que estaba practicando por entonces. En suconferencia de despedida de Dell the projects and collaborators began to form a majority. Suddenly OMA was globall". Koolhaas, Rem: "Globalization". En S, M, L, XL., op. cit. p. 369.

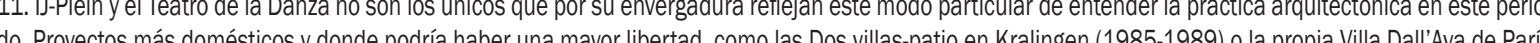
(1985-91), aparecen principalmente como ejercicicios del dominio retórico del lenguaje de Mies Van der Rohe y Le Corbusier. 
(Cómo de moderna es la arquitectura Holandesa?) Koolhaas lo señala con precisión revisando sus últimos proyectos en Holanda:

Algo parecido pasó con la arquitectura que diseñamos para el IJ-Plein. Esta hacía referencia explícita a la arquitectura moderna de entrequerras, aunque actualizándola o revisitándola de acuerdo a nuestras propias ideas de modo que esta arquitectura nuestra podría seguir funcionando a pleno rendimiento hasta el final del siglo" 12 .

$$
\text { Y continúa después: }
$$

"¿Cómo es posible, por el amor de Dios, que en un siglo enteramente condicionado por la inestabilidad y el ambio en el arte que mejor equipado está para reflejer a la sociedad, y en un lenguaje, aquel de la arquitectura, celebrado especialmente por su capacidad de transformación que a pesar de todo esto, edificios que se llevan casi cien años aun se parezcan tanto entre sí? Esto es 10 que entonces dio pie a la auto-crítica"

En 1987, Koolhaas advirtió que OMA había perdido algo en el camino. Recuperando algo del espíritu de Delirious New York el resultado de esta autocrítica es la contundente aparición de tres proyectos paradigmáticos a finales de los 80: Très-Grande-Biliothèque, Zeebruge terminal y ZKM ${ }^{14}$

Primera inflexión: Bigness, 1989

A mediados de 1970, el descubrimiento del Downtown Athletic Club de Manhattan inspiró en Koolhaas un punto de vista desde el que construir su discurso arquitectónico y urbano. El Athletic Club estaba lo suficientemente cerca de su especial sensibilidad hacia la liberación de la acción con la que se había formado, pero lo suficientemente lejos de las posiciones neo-utopicas ironicas, tan

presentes en su educación AA, y que pronto rechazaría tas su aprendizaje con Ungers' ${ }^{15}$. La lectura del rascacielos neoyorkino representaba entonces por tanto esa particular simbiosis arquitectónica entre permanencia for ad de acción ansiada por Koolhaas. En los 90 , Koolhaas re-elabora los intereses de Delirious New York con un ńnico párrafo conclusivo que lo acerca a sus preocupaciones intelectuales del momento. Este párrafo publicado en $S, M, L X$ y que se extiende como una Inea que atraviesa imágenes de las páginas del libro dice lo siguiente:

"La permanencia de incluso la mas frívola pieza de arquitectura y la inestabilidad de la metrópolis son incompatibles. En este conflicto la metrópolis es, por definición la vencedora; en su penetrante realidad la arquitectura queda reducida al status del juguete, tolerada como decorado para las ilusiones de la memoria y la historia. En Manhattan esta paradoja está resuelta de manera brillante: a través del desarrollo de una arquitectura mutante que combina el aura de monumentalidad con el desempeño de la inestabilidad. Sus interiores acomodan composiciones de programas de actividades que cambian constantemente e independientemente entre sís sin afectar a lo que es llamado, con accidental profundidad, la envolvente. La brillantez de Manhattan es la simplicidad de este divorcio entre apariencia y desempeño de la acción mantiene la ilusión de la arquitectura intacta, mientras que al mismo tiempo se rinde devotamente a las necesidades de la metrópolis"16

En bigness, escrito por Koolhaas en 1994, aparece este mismo tema del rascacielos neoyorkino pero revisado y adaptado a sus intereses presentes y en relación a proyectos recientes como Très-Grande-Biliothèque,

12. Koolhaas, Rem: "How Modern is Dutch Architecture?", op. cit. p. 161

13. bíd.

14. Cinco años después Koolhaas recuerda: "En 1978, In 1978, Bigness seemed a phenomenon of and for (the) New World(s). But in the second half of the beginning even for the rfinishedn continent. Against the background of Europe, the shock of Bigness forced us to make what was impliciti in Delirious New York expliciti in our work". Koolhaas, Rem: "Bigness". En S, M, L, XL, op. cit. p. 504 .

15. Koolhaas, Rem: "Field Trip. A(A) Memoir". En S, M, L, XL, op. cit. pp. 215-231. Espectro completo de las referenciias de Koolhaas de este primer periodo muchas de ellas opuestas entre si: Archigram, Peter Smithson, Cedric Price, Charles Jenks, Alvin Boyarsky, Elia Zengelis, Bernard Tschumi, Superstudio, So 16. Koolhaas, Rem: "Foreplay". En S, M, L, XL, op. cit. pp. 23-43.
Zeebruge $\mathrm{O} Z \mathrm{KM}^{17}$. El origen intelectual de bigness se mantiene sin cuestionarse en relación con la cultura arquitectónica de los años 70 , es decir, en sintonía con el planteamiento dialéctico marxista de la oposición entre arquitectura y metrópolis, y por extensión, de la dialéclica entre forma y cultura planteada por la teoŕa ortica marxista de Georg Simmel o Georg Lukács y que Manfredo Tafuri introdujo en la arquitectura'18 De hecho, en bigness está aún presente esa misma dialéctica arquiectura/metrópolis que planteaba Manfredo Tafuri en los 70 y principios de los 80 en La esfera y el laberinto o Arquitectura contemporánea. Ambos trabajos son narraciones construidas alrededor de esta paradóica dialéctica entre la arquitectura y la ciudad y que se resuelven a través de diversos proyectos críticos que van desde os dibujos del Campo Marzio de Giambattista Piranesi al Karl Marx Hof ${ }^{19}$. La dialéctica arquitectura/metrópolis no es el único punto en común entre Tafuri y Koolhaas. Al igual que Tafuri a mediados de los 70 , Koolhaas rechaza en bigness de manera explíita las propuestas de los grupos neo-utópicas como Archigram o Superstudio, siendo especialmente crítico con la obra de Yona Friedman ${ }^{20}$. Según Koolhaas, las dos principales líneas de defensa mostradas por estos grupos radicales, "desmantelamiento" y la "desaparición" -ambos intelectualmente seguros pero factualmente inoperantes- acabaron por convertirse en tristes metáforas de "dominio" crítico de la subsiguiente generación de arquitectos"

17. Koolhaas, Rem: "Bigness". En S, M, L, XL, op. cit. pp. 494-517.

18. Hays, Michael: "Critical Archilitecture between Curture and Form."En Perspecta. 1984, No 21. pp. 14-29.

19. Taturi, Manfredo y Dal Co, Francesco: Modern architecture. New York: Rizzoli, 1979. La narración completa del libro comienza por dos polos opuestos, (a) pp. 504-505. Del mismo modo, comentando el trabajio de Archizoom y Superstudio, Tafuri piensa que la "la liberación a través de la ironía se sigueve revolvivendo sobre el mismo terreno ya cubierto por las vanguarclias de años anteriores", y que las nuevas utopias que han promovido este "salto privado en el sublimado

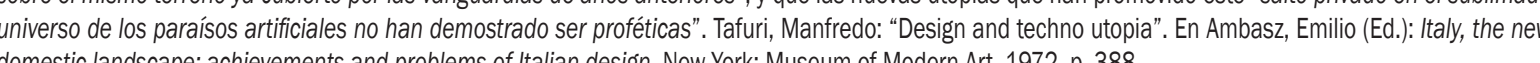
(2.

pp. 231 y siguientes

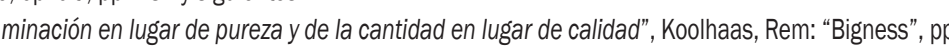


3. Un ejemplo del empleo de la sección libre. Termi-
nal martitima de Zeebruggege, 1989 . (a) cebrugge, 198

4. Bigness como condensación de un campo conti-
nuo. Terminal martitima de Zeebrugge, 1989 .

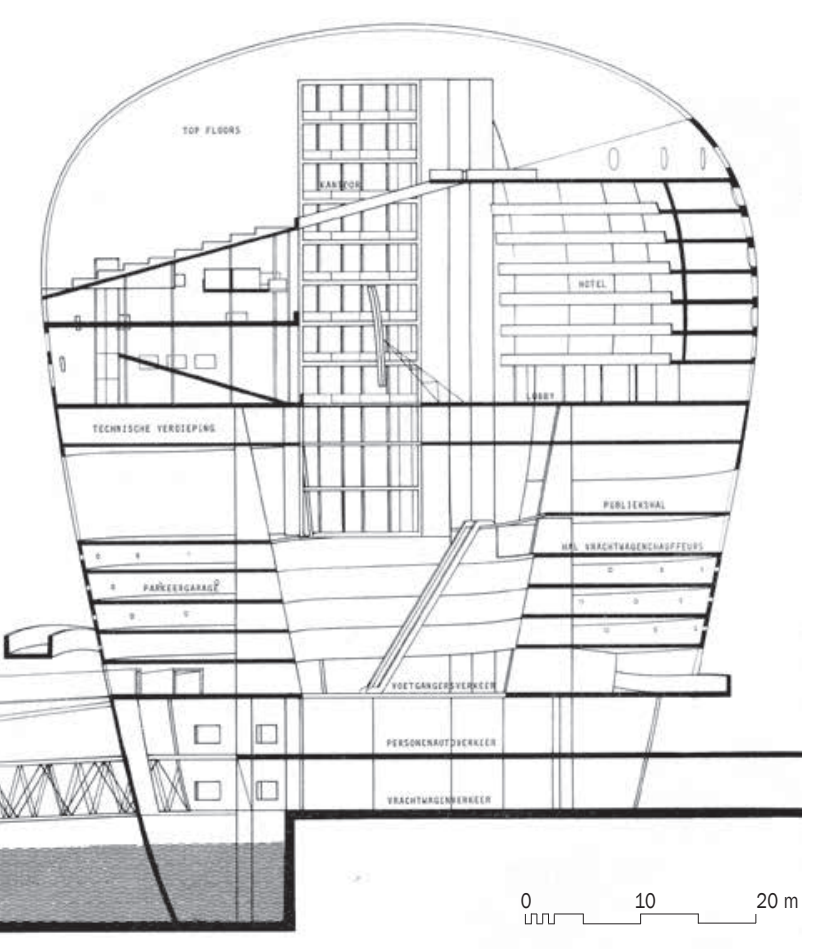

protesta por exceso, como una huelga a la japonesa. La inteligencia del argumento de bigness es su capacidad para mantener un compromiso con la flexibilidad, la fluidez y la naturaleza informal de las prácticas espaciales liberadas pero sin rechazar la presencia de la forma arquilectónica, como si lo hicieron finalmente las arquitecturas utópicas y radicales de los 60 y 70, desde Archigram a Haus Rucker Co. Con bigness Koolhaas trata igualmenlos que anteriormente también habian intentado facilitar esta libre acción del habiliante. Tal es el caso de algunos espacios no programados para su libre apropiación. Sin embargo, la experiencla de estos espacios tanto en la canónica Universidad Libre de Berlin de Candils, Josic Woods (1963-74) Como en otros experimentos posteIngeniería de la Universidad de Bath de Alison y Peter e de superar otro escollo su Kdo por algunos arquiteoexperimentos del Team $X$, donde a menudo se dejaban
Smithson (1978-88), es que estos espacios no programados no son de libertad sino residuales, y tendentes a su marginalización progresiva por la ausencia de fricción existente"

En bigness, el nuevo arreglo entre forma, programa y libertad se produce gracias a lo que Koolhaas denomina una "lobotomía" entre la apariencia externa y el desempeno de la acción en el interior a la que lo grande en sí da lugar. En particular, en el edificio grande, la distancia entre $e$ núcleo interiory la envolvente externa es tal que se produce una falla de organicidad que libera las relaciones entre del artes y el todo, manteniendose sin embargo la idea biliza la o del conjunto, como una gran masa que esta(lo interio) La entre lo estálco (extenion) y lo cambiante objeto ión. La enancipacion de la envolvente como un rorganizaín continua del gran interior del edficio en o que Rafael Moneo ha venido a llamar pariculicio en

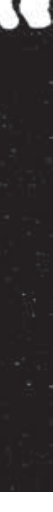

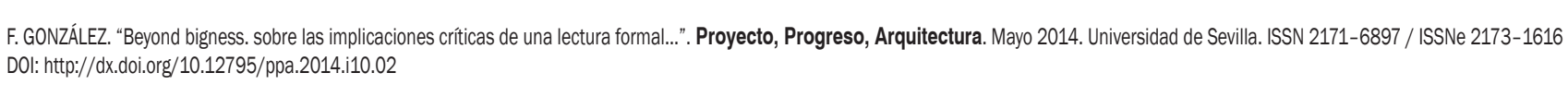

como la "sección libre"25 (figura 3). En 1989, tres proyectos paradigmáticos de OMA, Très-Grande-Bibliothèque, Zeebrugge y ZKM, parecen abrazar abiertamente este concepto de bigness. Así por ejemplo, lo que permite la libertad programática de Zeebrugge según Koolhaas es su iconicidad externa -la intersección de un cono invertdo y una esfera- que emerge desde el suelo casi como ( eja terntorial sobre el que se sitúa (figura 4). Del mismo modo, lo que hace posible la excepcional sección libre de la Tres-Grande-Bbbliotheque para el concurso de Birloca nacional de Francla es la enorme distancia que percleo de la construcción toma respecto a la lachada permitiendo relaciones espaciales más libres e inorgáncas en su interior. Por último, lo que permite el libre apilimiento estuctural del ZKM es la malla continua que envelve el exterior deledificioy que representa la piel sobre la que la instifucion proyecta pelliculas como su emblema medialco. Pero lo que es más importante. el proceso de acumulacióny congestion que le han permitico al edificio alcanzar la masa crlica para ser grande da lugar a que en esta sección libre se den fricciones, solapes y superposiciones entre los distintos programas capaces de genera situaciones de indeterminación entre programa y espacio. Es desde esta indeterminación programática desd donde parte la libertad de acción de sus habitantes si que la programación del espacio desaparezca. La crítica de bigness consiste por tanto en la posibilidad de una exploración continua del programa que libera la acción del constrenimiento normativo de la forma arquitectónica a traves de solapes y fricciones que lo vuelven programabiguo, y sin que la forma arquitectónica en

26. Juego de palabras con la noción de basura espacial como un espacio sin cualidad, sin intensidad, sin determinación. Koolhaas, Rem: "Junk Space". En

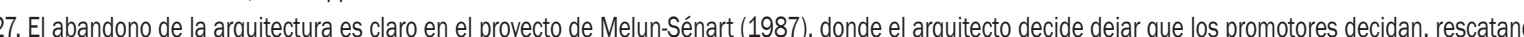
sólo puntos particulares en el territorio. Ver Koolhaas, Rem: "Competition Entry for the New Town Melun-Senart". En S, M, L, XL, op. cit,, pp. 973-989. 28. Ver Koolhaas, Rem: “Loop-trick. Universal Modernization Patent". En Content, op. cit, p. 76.

29. Su más famoso lema es un diagrama que promueve la "X" (multiplicación espacial, como superposición de planos oblicuos), frente a la " "" (sumatorio de espacios, de la intersección planos verticales y horizontales). Ver: Johnston, Pamela (Ed.): The Architecture of Claude Parent and Paul Virilio: The Function of

30. Ver: Virlilio, Paul: “The Oblique Function". En Architecture Principe. Febrero 1966, $n^{\circ} 1$. Reeditado en: Ockman, Joan: Architecture Culture 1943-1968. New York: Rizzoli, 1993. pp. 408-410.
Loop (1): Kunsthal II, 1990

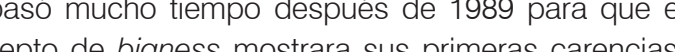
El ejemplo más claro es Congrexpo en Lille (1990-4), un tivio concebido para producir una diversidad de evenO y actividades no pre-programadas que termino enrian más adelante como junkspace (espacio basura) a gún las teorlas formuladas en bigness, la iconicidad

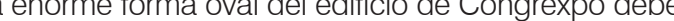
su profundo interior como infinitamente . Sin embargo, el problema es que si bien ( arquitectónicamente con el interior, que se ha dejado to(amente a merced de aquellos impulsos que dominan pacio pacio basura. En resumen, con bigness la forma arquiinterior: y nada asegura que lo que reproduzca sistemáicamente no sea la condición vulgarmente convenciona apas par loop-tick'. Este fue utilizado por primera vez para el proyecto del Kunsthal, probablemente muy bajo

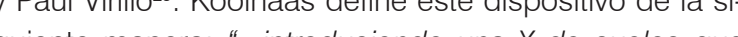

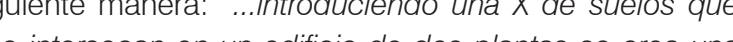
super plantas se crea una . parece estar todavía A pesar de que esta definición parece estar todavía 政 


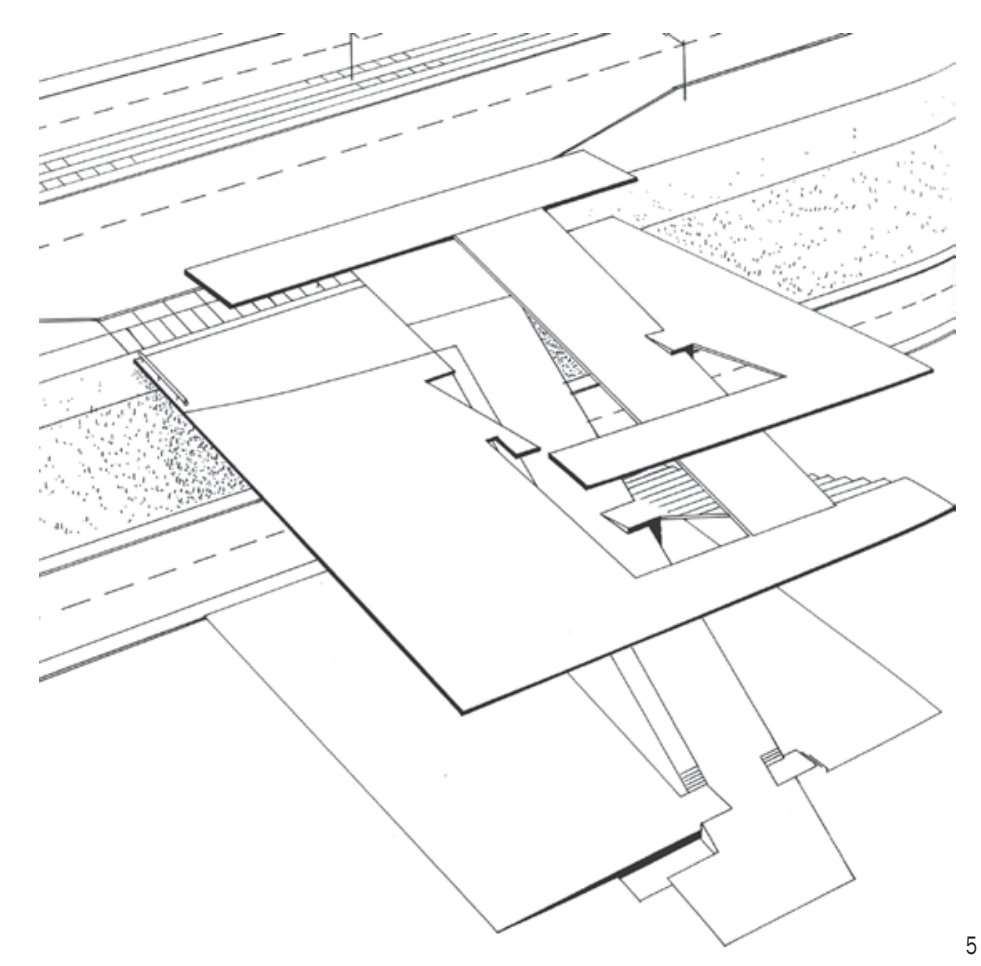

5. Kunsthal II, recorrido helicoidal en el diagrama axonométrico del edificio.

ma del recorride Kanpiral del II (1990-19993): Diagranes en S, M, L, XL. Este recorrido termina y comienza de nuevo cuando aparece el ascensor, que cierra fragmento de la obra Esperando. A Godot que corre de con el paseo a través de imágenes, el fragmento se repite desde la página que muestra el ascensor (jalas!). 7. Mat building como un tapiz continuo. OMA, Vivienxus World, Fukuoka 1991. demasiado cerca de Parent y Virilio, y se refiere principalmente al valor transgresor que puede tener lo oblicuo como el borrado de las barreras verticales y horizontales que los forjados y muros establecen en arquitectura, este recurso representa el primero de los intentos de Koolhaas para tratar de reorganizar la estructura interna de sus edificios.

En realidad, el dispositivo denominado como "Iooptrick" no sólo funciona como Koolhaas lo describe en esta breve referencia citada anteriormente. Si miramos con atención la forma en que se utiliza especificamente en el Kunsthal, se comprende mejor por que se le llama loop, y no "X de suelos que se intersecan" o "superficie continua." En el Kunsthal, las rampas creadas están interconectadas siguiendo un recorrido helicoidal que conduce a los visitantes a traves del edificio, similar al diagrama de circulacion del Museo Guggenheim de Nueva York de Frank Lloyd Wright. El suelo inclinado organiza y estructura por tanto la forma en la que entendemos el interior, al pismo tiompo qué traza un delberado procio. En la seccín que se descibe elKunsthat en S.M. pario. Por un lado, las imágenes que Koolhaas utilizan para liustrar el proyecto van siguiendo el recorrido espira que también se muestra con llechas sobre las plantas del mismo. Este recorido fotográfico se acompaña de anotaciones explicitas respecto a cómo realizar el paseo espiral del tipo "camine hacia arriba", "gire a la dere cha", "salga bajo el baloón", haciendo un claro entasis en esta estructura particular del edificio (figura 5) 31. $^{31}$ Lo que a prior paroce sin embargo más inexplicable es que as instrucciones explicilas para este reconido espiral, que aparecen en letra pequeña, estén acompañadas por una larga cita en grandes caracteres que provienen Lsperando a Godot de Samuel Becketl

La configuración del ediricio no es sólo helicoidal, sino más particularmente un loop o bucle. Como tal, es un circul pa cerrado, algo que se repite. La narración que se sigue en $S, M, L, X L$ para desoribir esta cualidad en $\Theta$

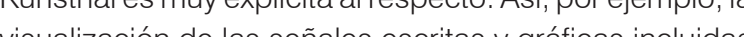
en su recorrido arquitecónico evitan toda posiblidad le encontar un puto de parida u otro de posizacion,

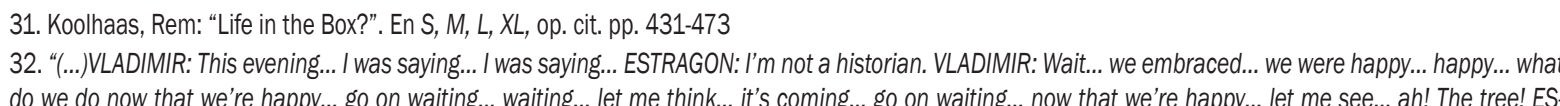

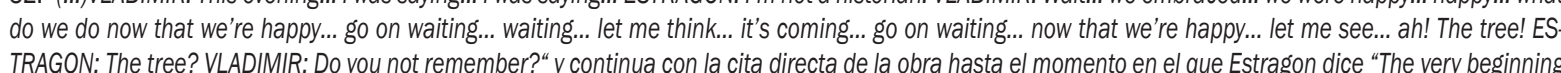
TRAGON: The tree? VLADIMIR: Do you not remember?" y continua con la cita directad de la obra hasta el momento en el que Estragon dice "The very beginning

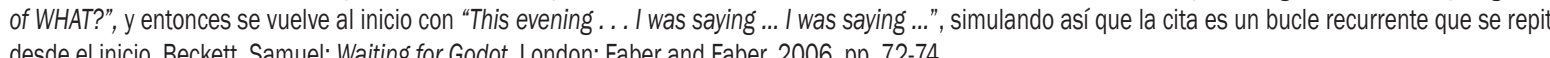
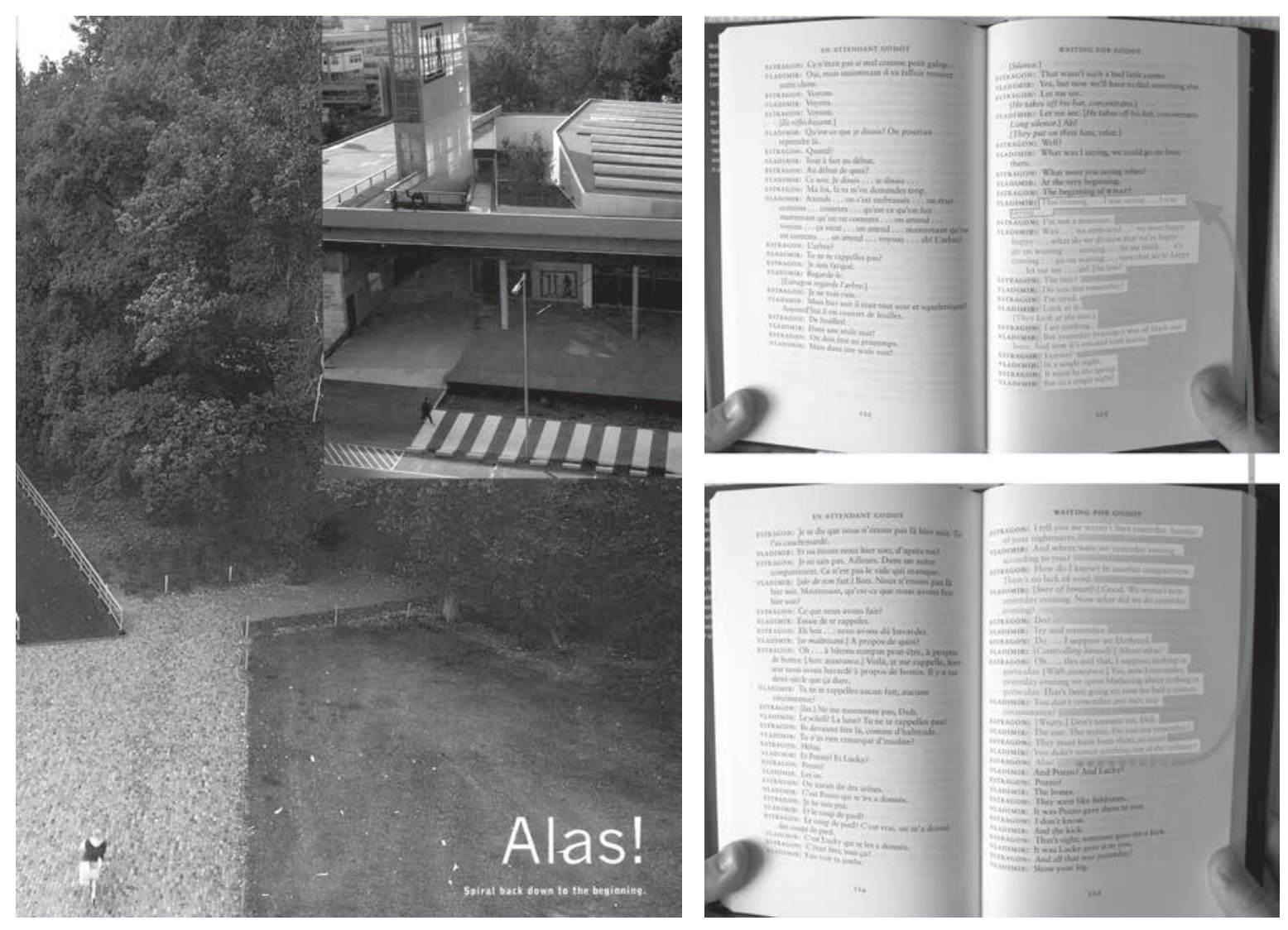

haciendo ver a los visitantes que este recorrido es una ruta conlinua y cerrada, que se reple sin cesar como un bucle. La clla de Becketl de Esperando a Godot es tambièn un bucle que se repite, y que se reinicia precsamente cuando leguemos a enganche que cierra este bucle infinito (figura 6 ).

De este modo, con el dispositivo del loop el edificio recupera su interior, dando una estructura básica a su contenido. Éste ya no se da desordenadamente disperso bajo la envolvente del edificio, sino que está conectado a traves de una suave secuencia. Si los edfilos concebidos desde bigness dependian de una "lobotomía" entre el interior y el exterior, donde el interior respondia a la condición cambianto de la mertopols ye exp

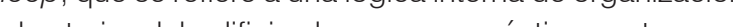
el exterior del edificio desaparece practicamente como dad m. Con el loop el edrio se entrenta a la inestabittural interna que organiza su contenido a través de cambios.

Mat Buildings (1): 1990

La lógica del loop no va ser la única que Koolhaas utillce para revisar el concepto de bigness. A principios de

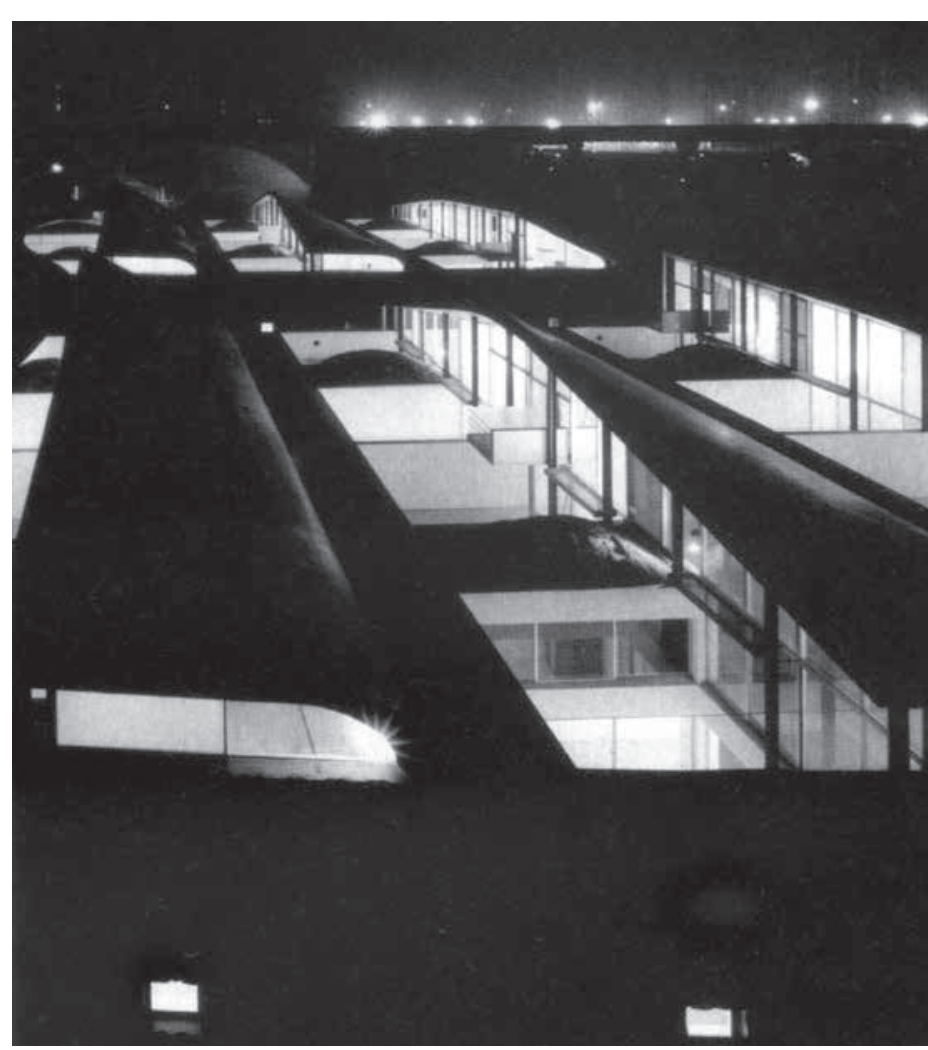


8. Kunshal II, contra-programación. 9. Dabiama paranoico-crtico del Kunsthalll, on las Esperando a Godot ("Don't torment me, Didi) y las indicaciones de circulación explicitas "Exit under the balcony").

os 90 el holandés estaba también explorando estrucfuras organizadas a través de patios e interrelaciones horizontales, en una serie de proyectos que se podrían
clasificar como mat buildings: edificios compactos y de clasilcar como ma bullings: ed cilos compactos y de del alida que basan su logica cons civa en

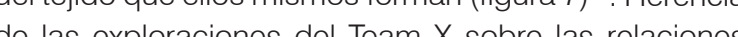
de las exploraciones del Toun $x$ sobre las relaciones enre la cońc estructuras similares eran un tema, knotans y ños 1960 y 1970 siendo la Universidad libre de Berlín de Candilis, Josic y Woods el ejemplo fundamental de sta preocupación arquitectónica. Educado en la AA,

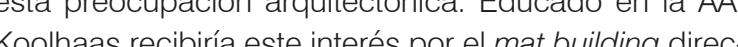
Koolne de Poter Smithson, aunque su formalizacín no apareció en su obra hasta principios de la dócada de los 90 con proyectos como el Nexus World en Fukuoka (1989-91) o en el Hotel y Centro de Convenciones en Agadir (1990) ${ }^{34}$

En $S, M, L, X L$, Koolhaas define la cualidad como mat-building de las viviendas de Nexus World de la siguiente manera: " tapices continuos donde las casas nunca se convierten en objetos" y donde " I sustancia centrífuga de la arquitectura moderna se condensa para generar la forma urbana"35. Estos tapices o mats también abarcan el argumento de una condensación que produce una masa crítica -como bigness- pero que se rige por ciertas normas internas como, por ejemplo, patios Al igual que en el caso del loop, los edificios concebidos como mat buildings no tienen exterior porque dependen sólo también de su propia lógica interna de conexiones Los edificios que se organizan como mat buildings serán la otra crítica y alternativa a bigness: manifiestan un primer intento de incorporar el edificio en el suelo público, de abrirlo al exterior, mientras que al mismo tiempo se recupera también la estructura espacial del interior.

oop (2)

el mat building funciona como un conjunto de conexiones a modo de red o matriz, el dispositivo del loop trabaja con un tipo de conexín hincal. El mat bulling busca la pando as la distibución de fuerzas, disolvichdo y disiEloop, sin embargo a pesar de que su diagram idea

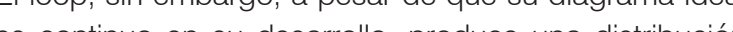
crispada de fuerzas en la relación con las diferentes supericies programíticas con las que se cruza. El loop se convierte entonces en un dispositivo (siguiendo la terminología de Michel Foucault) porque cuando su diagra ma ocupa el volumen interior del edificio activa detemnadas relaciones socio espaciales a través de procura una máxima ficcín ente espacios/programas. De esta orma la vocación de ba conlinuidad lineal de loop es a producir encuentros inesperalos en su seccín, a trav́s le la confrontación el desplazamiento, el voyeurismo y otras relaciones que aparecen transure elmente agitando su diagrama cuando éste se desarrolla a través del cio. El dispositivo del loop toma por tanto como ventaja previsibilidad de su diagrama y la imprevisibilidad de las acciones que éste genera en su transversalidad espacial Es fiel a la idea de Georges Bataille de transgresión con romper la norma pero entendiendo al igual que Bataille que para ello la norma debe de existir y que sólo si uno sabe a dónde va puede salirse del camino ${ }^{36}$ El loop es una línea continua que produce oportunidades, un camino univoco que se abre la distracción, un registro transversal que invita desviación.

La inteligencia del argumento del dispositivo del loop es que se recupera la arquitectura interior que se habí perdido con el concepto de bigness, pero mantiene su sentido crítico. De hecho, el dispositivo del loop mejora todas las técnicas de trans-programación, re-programación o contra-programación, cuyas fricciones producen

33. Smithson, Alison: "How to recognise and read a mat-building". En Architectural Design. 1974. Vol. XLVV, № 9. pp. 573-590.

34. El mat-building habia aparecido ya de alguna forma en Koolhaas con propuestas como La Villette (1982). Eaunque es mas un desararollo horizontal del New York Downtown Athletic Club. Ver Koolhaas, Rem: "Compettion Entry for Parc de la Villete, Paris, 1982". En S, M, L, XL, op. cit. pp. 895-934.

35. Koolhaas, Rem: "Housing in Fukuoka, Japan, 1991". En S, M, L, XL, op. cit. p. 86.

6. Bataille describio esta relación paradojicca en La Parte Maldita, fundamentándose principalmente en su teoría sobre el erotismo. Para Bataille la trans

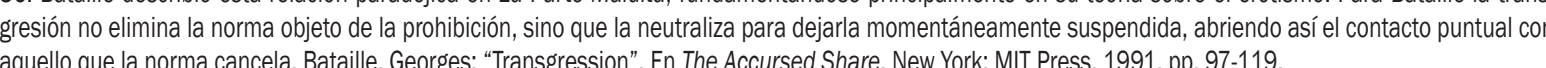

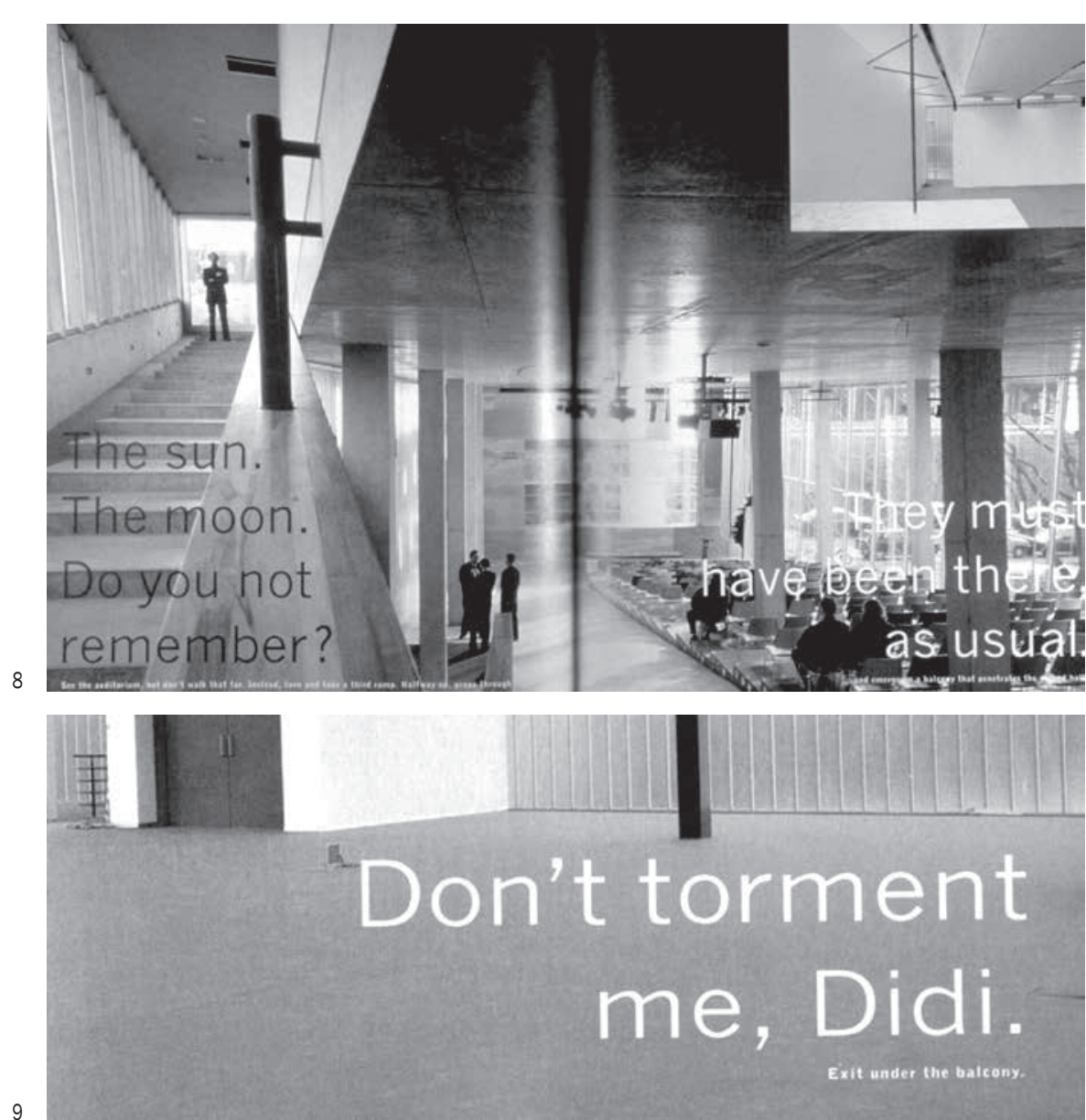

eventos y acción libre no programada y que Koolhaas esperaba del rascacielos neoyorkino. La acción es generada por la superposición, confrontación, renovación y mezcla de los diferentes programas a lo largo de esta circulación continua que crea situaciones de contradicción ambigüedad o duplicidad, y que dan lugar a la emergenKunsthal es donde Koolhas utiliza por primera vez este dispositivo. En el edificio los diferentes programas se superponen, mezclan e hiper-conectan, generando e sutando continuamente a la divergencia la desviación y la distracción respecto a la senda trazada por la espiral continua La sala de conferencias, por ejemplo, se enfrenta la circulación de vehículos en el estacionamiento y a mismo tiempo, está atravesada por la circulación de la missción. Estas superposiciones y contra-programaciones entre funciones contradictorias entre sí (como el parkinges auditorio y la circulación de la sala de exposiciones) están destinadas a producir estas desviaciones, distracciones,

enfrentamientos fortuitos y relaciones inesperadas, y por lo tanto, a la liberación de la acción de los individuos respecto a la trayectoria fijada por la espiral (figura 8) La neta recín y nos ayuda a entender el por qué de a presencia de Beckett. El doble juego de indicaciones para recorrer el loop nos habla de su condición ambiva lente: por un lado, como recorrido expĺcito, continuo y pragmático que sigue la espiral linealmente por el camino más directo, y por otro, como recorrido abierto, hiper-conectado, generado a través de las desviaciones y distracciones que la fricción de esta espiral genera por los espacios que recorre de manera irracional indeterminad y en definitiva, absurda, y a la que la de cita de Becket hace referencia. Este doble juego de indicaciones representa el diagrama paranoico-crítico sobre el que se fundamental el edificio: la mezcla paradójica entre la máxma explicitud pragmática y el máximo absurdo irraciona $(\text { figura } 9)^{37}$

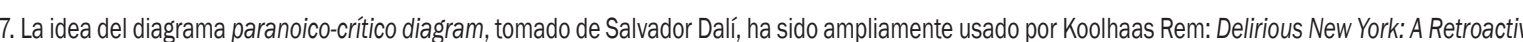
Manifesto for Manhattan, Londres: Academy Press, 1978, pp. 235-246. 


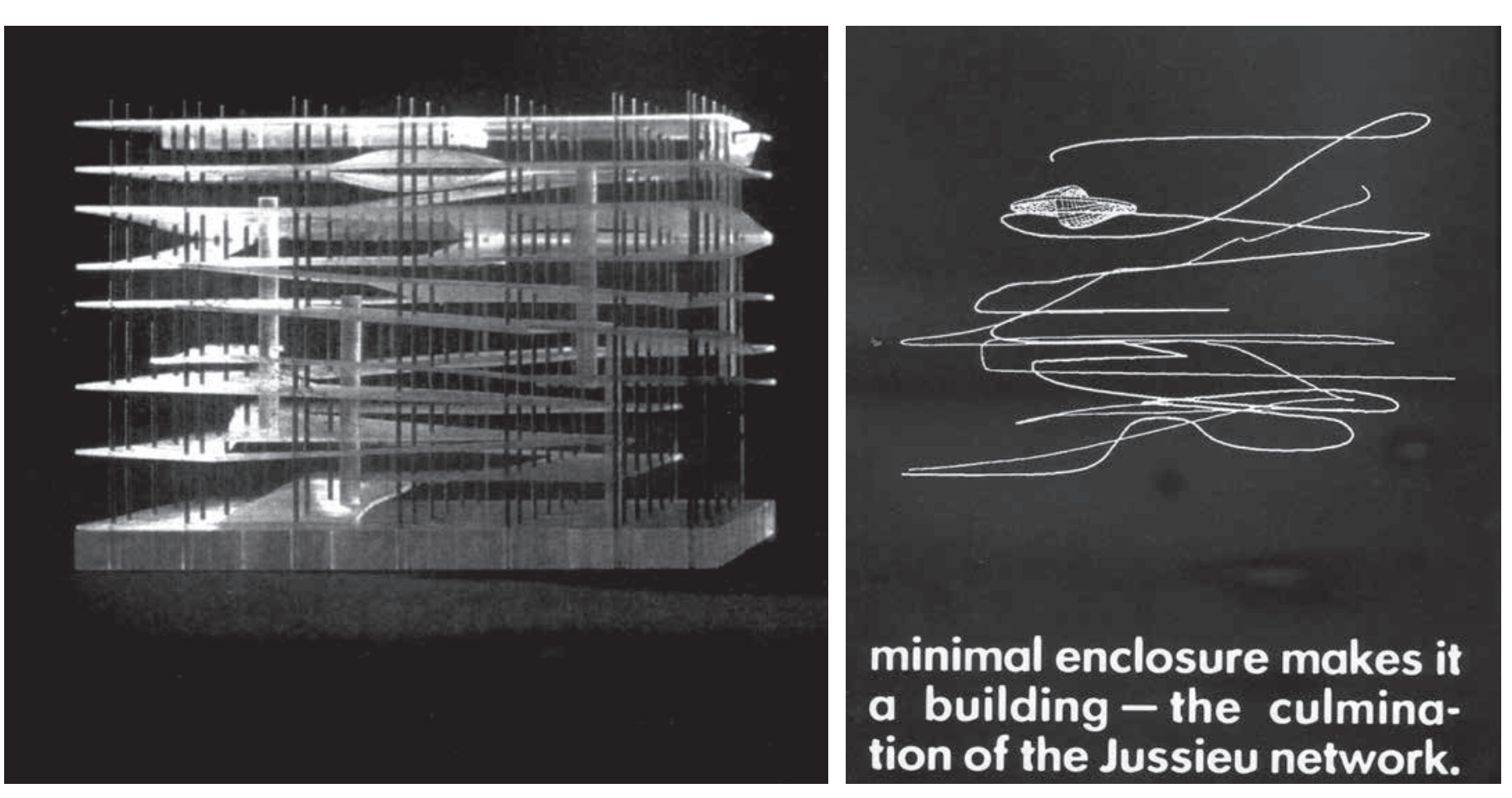

Segunda Inflexión: 1993 Jussieu

La propuesta de la Biblioteca doble de Jussieu es el proyecto en el que se seguira desarrollando estas exploraciones formales. El proyecto aparece como una especie de intersección entre los conceptos de mat building y bigness que se convierten en loop como resumen de los conceptos vistos hasta ahora (figura 10). Assi, de acuerdo con la idea de bigness, en Jussieu el programa de las dos bibliotecas se pliega y superpone para generar una mayor densidad que genere presencia urbana y congestión programática ${ }^{30}$. Contraliamente a bigness, sin embargo la lobotomía entre interior y exterior desaparece porque es

el suelo social publico, la calle, lo que es plegado y retorque Koolhaas denomina como Inside-Out City ${ }^{39}$. Del mismo modo, de acuerdo con la idea del mat-building, Jussieu es una urdimbre social que genera conectividad ${ }^{40}$. Pero contrariamente al mat building, Jussieu tiene una referencia lineal en su desarrollo espacial que no funciona como una matriz plana, sino como la helice que inspiro al Kunsthal. De este modo la superficie plegada de Jus sieu genera un reconido arquilectónico continuo que arcula la espacilda do del edificio (figura 11). Koolhaas lo explica de la siguiente

38. " "Siel problema del presente podium es la dispersión, entonces esta reconfiguración genera, con la misma substancia, concentración. Para crear más Library". En S, M, L, LL, op. cit. pp. 1316-1328.

39. Koolhaas, Rem: "Inside-Out-City. Universal Modernization Patent". En Content, p. 79.

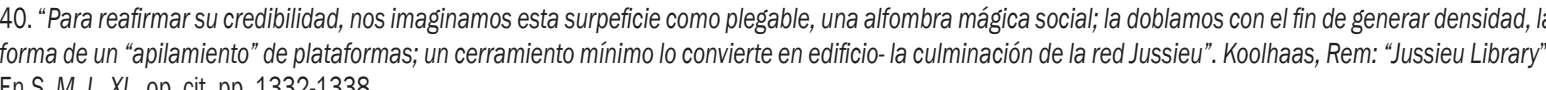
ESS. ML XL op cit pp. 1332-1338.

manera: Todos los planos están conectados por una sola trayectoria, un bulevar interior deformado que expone y se relaciona con todos los elementos programá(thos. El villante se conviene en un lianeur de Baudeare, que inspecciona y se deja seducir por un mundo de libros e información - por el escenario urbano"4. En Content, Koolhaas describe el funcionamiento de este edificio de manera aún más directa: "Plegar una calle para generar boulevard interior vertical que se expone se relaciona con todos los programas en una única se cuencia"42, lo que implica elementos provenientes tanto del loop como del mat building

La biblioteca de Jussieu culmina este proceso de investigación sobre la forma arquitectónica y su vinculación con la libertad de acción del habitante. Como un dispositivo critico, la biblioteca aprovecha los mecanismos de contra-programación, re-programación o trans-programacion previamente explorados, generando un interior fircoionado en el que según Koolhaas este flâneur urbano" se movería y actuaria libremente. En opinión del arquitecto: "... las construcciones especificas de las bibliotecas tendran un potencial ilimitado para la expresión individual y la diferencia"

Loops and beyond

Si bien el concepto de mat building ha sido ampliamen-

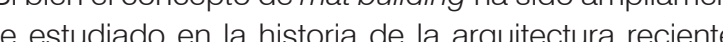

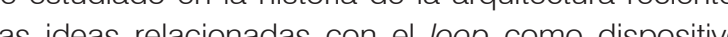
parecen haber recibico menor a cicín cispasivo menes, no han recibico menor atención critica, o a parte substancial del discurso de Koolhaas. Tal vez esta

41. Koolhaas, Rem: "Uussieu Library". En S, M, L, XL, op. cit. pp. 1338-1341 22. Koolhaas, Rem: "Inside-Out-City. Universal Modernization Patent". En Content, op. cit. p. 79.

43. Esta cita anterior, insisitiendo en el valor de una calle interior, nos Ileva de nuevo a la influencia de Alison y Peter Smithson, cuya obra arquitectonica co

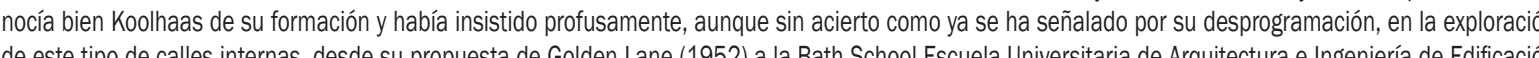

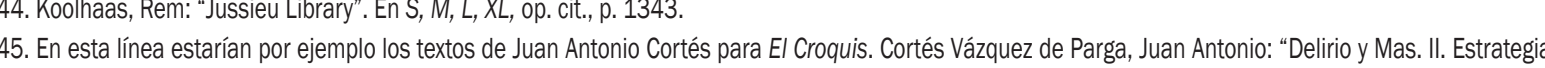
frente a Arquitectura". En El El Croquis. 2006, $N^{\circ} 131-132$. Otro texto paradaigmático en este sentido sería el que publicó Antón Capitel sobre la Casa de la Múusica de Oporto en 2007 aunque Capitel no es capaz de realizar una interpretación clara sobre esta estructura espacial del edificio. Capitel, Antón: "La Casa de la
Música de Oporto 0 el Formalismo de la arguitectura de OMA". En Arquitectura. 2007, № 348. Madrid: Colegio de Arquitectos de Madrid. pp. 102-109. En Música de Oporto. 0 el Formalismo de la arquitectura de OMA". En Arquitectura. 2007, № 348 . Madrid: Colegio de Ar
ambos casos parece que la descripción explíita de la forma no es suficiente para acceder a su función o propósito.

Omisión pueda deberse al mismo modo en el que la ha hecho bastra rectura tormal de la arquiltectura se (on

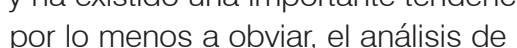
forma como un hecho relevante en la escritura crític

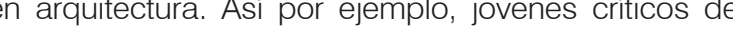
Whitedura norteamericanos como Somol, Speaks o

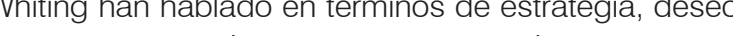
opolencia, refuglándose en elvalor en si mismo del en-

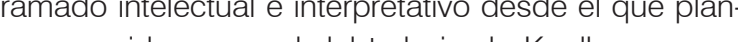

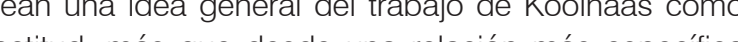
achich, más que desde una relación más especifica

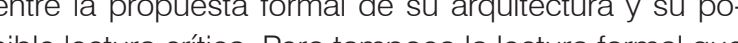
ale lectura critca. Pero tampoco la lectura tormal que (o pras aulores de una generación anterior han seguido recicando, por ejemplo, en España, ha conseguido relacionar las exploraciones de Koolhaas con sus ente estas otras lecturas se (ivo dudado a menúdo limitadas a ejercicios descripin ino en aro de ideas en el que Koolhaas se mueve, a Aunque quizá el motivo principal de esta ausencia se la debamos al propio Koolhaas. Salvo los breves

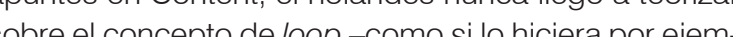
plo con el de bigness-, sin quedar demasiado caro 
cuál pudiera ser el motivo de tal olvido46. Sea como fuere, el silencio de Koolhaas no impide reconocer hoy mide y complementa bigness en una parte importante de

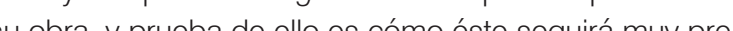

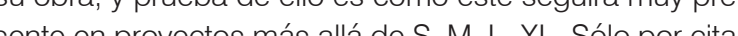
lgunos ejemplos el loop volveri a aparecer en el Edrcatorium de Utrecht (1093-00), y posteriomente en 105 car Ḿs adelante tambín a arece de manera (loguente Kar

en el vestíbulo que gira alrededor de la Casa da Música de Porto (1999-2005) hasta llegar finalmente al edificio Colven Befing (2002-2008). Es con este edficio que a ración entre loop y bigness que ál mismo denomina como loop skyscrape ${ }^{47}$. Pero es también con el CCTV que se evidencia ya cómo la exploracín formal comenzada quince años atrós empieza a agotarse absobich zach qunce anos atrás empieza a agotarse, absobicha réricas de aquelas invenciones fom des de ayer que
Francisco González de Canales (Sevilla, 1976). Arquitecto (2001), Master in Design (with Distinction), PhD (cum laude) (2007) estudió arquitectura en Sevilla, Barcelona y Harvard University y trabajó para Foster+Parthers y Rafael Moneo. En 2004 establece su oficina profesional Canales \& Lombardero con Nuria Álvarez Lombardero. Desde 2012 es Profesor Titular de Composición Arqu lectonica de la Universidad de Sevilia. Proféesor de proyectos y de historia y teoria en la Architectural Association de Londres, dond fue también coordinador cultura (AACP Coordinator) entre 2008-2012. Entre 2001 y 2006 Fue director de la revista Neutra, de que formó parte de su comité editorial hasta su disolución en 2011, y ha colaborado con revistas como Abitare, Archithese, ARQ Arquitectura COAM, Arquitectura Viva, Domus, Journal of Architectural Eduaction, RA o Summat. Entre sus publicaciones recientes (2014) ambos Wor

\section{Bibliografía}

Aureli, Pier Vittorio: "The City Within the City". En The Possibility of an Absolute Architecture. Cambridge, MA: MIT Press, 2011. pp. 177-228. Baird, George: "Criticality and its discontents". En Harvard Design Magazine. Otoño 2004-Invierno 2005, № 21. pp. $27-28$. Bataille, Georges: "Transggression". En The Accursed Share. New York: MIT Press, 1991. pp. 97-119. Capitel, Antón: "La Casa de la Música de Oporto. 0 el Formalismo de la arquitectura de OMA". En Arquitectura. 2007, n 348 . Madrid: Colegio de

Eisenman, Peter: "Postfuncionalism". En Oppositions. 1976, n 6. pp. 6-12.

Hays, Michael: "Critical Architecture between Culture and Form". En Perspecta. 1984, nº 21. pp. 14-29.

Jow

his. 2006, № 2. pp. 120-127.

m: Content. Colonia: Taschen, 2002.

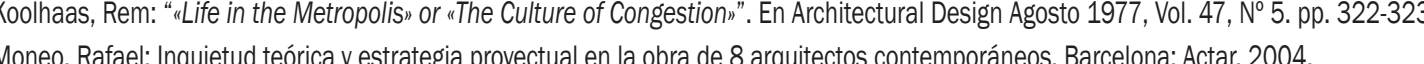

Moneo, Rafael: "Inquietud teórica y estratategia proyectual en la obra de 8 arquitectos contemporáneos. Barcelona: Actar, 2004.

Somol, Roberty Whiting Sarah. "Notes on the Doppler Effect and Other Moods of Modernism". En Perspecta 2002, № 33 , pp. 72.77.

Speaks, Michael: "Design Intelligence and the New Economy", en Architectural Record, January, 2002, pp. 70-72.

Speaks, Michael y Hadders, Gerard (Eds.): Mart Stam's Trousers. Rotterdam: 010 Publishers, 1990

Tafuri, Manfredo: "Design and techno utopia". En Ambasz, Emilio (Ed.): : taly, the new domestic landscape: achievements and problems of Italia

Tafuri, Manfredo y Dal Co, Francesco: Modern architecture. Translation from the Italian by Robert Erich Wolf, New York: Rizzoli, 1979.

Tschumi, Bermard: "Space and Events". En Architecture and Disiunction. Cambridge, MA: MIT Press, 1994. pp. 140-152.

Virilio, , Baul "The Oblique Function". En Architecture Principe. Febrero 1966, № 1 (reeditado en Ockman, Joan: Architecture Culture 1943-1968. New
York: Rizzoli, 1993. pp. 408-410. 


\section{Autor imagen y fuente bibliográfica de procedencia}

Información facilitada por los autores de los artículos: página 17, 1 y 2 (Loghem, J. B. van: Bouwen / Bauen / Bâtir / Building Holland. Amsterdam: Kosmos 1932); página 18, 3 (Wiebenga archive (69-70), NAi, Rotterdam); página 20, 4 (Jan Molema), página 21, 5 (http://www.spotzi.com); página 22, 6 (Loghem, J. B. van: Bouwen / Bauen / Bâtir / Building Holland. Amsterdam: Kosmos 1932; Schütte-Lyhotski Archiv, Universität für angewannte Kunst, Vienna over a cadastral drawing on the internet: http://nah.cuzk.cz. Composed by Peter Bak and Jan Molema); página 23, 7 (Loghem, J. B. van: Bouwen / Bauen / Bâtir / Building Holland. Amsterdam: Kosmos 1932); página 24, 8 (Private collection Jan Molema), 9 (Jan Molema), 10 (Duiker Archive, NAi, Rotterdam); página 25, 11 (Van Loghem Bouwen / Bauen / Bâtir / Building Holland. Amsterdam: Kosmos 1932; C.A. Alberts and E.J. Jelles, Duiker 1890-1935, Forum, Amsterdam 1972); página 26, 12 ( Photo by courtesy of Arie den Dikken), 13 (Private collection Jan Molema); página 27, 14 ( Loghem, J. B. van: Bouwen / Bauen / Bâtir / Building Holland. Amsterdam: Kosmos 1932); página 28, 15 (Section from drawing in Duiker Archive, NAi Rotterdam); página 30, 16 (Multi-layer drawing on the basis of Duiker's site plan in Van Loghem Bouwen / Bauen / Bâtir / Building Holland. Amsterdam: Kosmos 1932. Composed by Jan Molema and Peter Bak); página 35, 1 y 2 (Francisco González de Canales); página 38, 3 y 4; página 40, 5; página 41, 6 (izda) (Koolhaas, Rem y Mau, Bruce: S, M, L, XL, Nueva York: The Monacelli Press, 1994), 6 (drcha) (Francisco González de Canales); página 41, 7; página 43, 8 y 9; página 44, 10 y 11; (Koolhaas, Rem y Mau, Bruce: S, M, L, XL, Nueva York: The Monacelli Press, 1994); página 49, 1 (Le Corbusier. En Boesiger, Willy. (Ed.): Le Corbusier Oeuvre complète. Volumen 1. 1910-29. 15a ed. Basilea: Birkhäuser Publishers - París: Fondation Le Corbusier, 1999. p. 189) ; página 51, 2 (Le Corbusier: Dibujo original del autor. FLC 10910. Fundación Le Corbusier. París, 1931), 3 (Le Corbusier: Fotografía del archivo de la FLC. FLC L2-4-41. Fundación Le Corbusier. París, s/f.); ; página 52, 4 (Le Corbusier. En Boesiger, Willy. (Ed.): Le Corbusier Oeuvre complète. Volumen 4. 1938-4. $11^{\mathrm{a}}$ ed. Basilea: Birkhäuser Publishers - París: Fondation Le Corbusier, 1999. p. 139) ; página 53, 5 (Le Corbusier: Dibujo original del autor. FLC 19238. Fundación Le Corbusier. París, 1936); página 54, 6 (Le Corbusier. EnBoesiger, Willy. (Ed.): Le Corbusier Oeuvre complète. Volumen 5. 1946-52. 11ª ed. Basilea: Birkhäuser Publishers París: Fondation Le Corbusier, 1999. p. 37) ; página 55, 7 (Le Corbusier: Dibujo original del autor. FLC 32294. Fundación Le Corbusier. París, 1951), 8 (Le Corbusier: Dibujo original del autor. FLC 2892. Fundación Le Corbusier. París, 1951), 9 (Le Corbusier. En Boesiger, Willy. (Ed.): Le Corbusier Oeuvre complète. Volumen 5. 1946-52. 11ª ed. Basilea: Birkhäuser Publishers - París: Fondation Le Corbusier, 1999. p. 121) ; página 56, 10 (Le Corbusier. En Petit, Jean. (Ed.): Un couvent de Le Corbusier. París: Éditions de Minuit, 1961. p. 112); página 58, 11 (Le Corbusier. EnBoesiger, Willy. (Ed.): Le Corbusier Oeuvre complète. Volumen 7. 1957-65. $7^{a}$ ed. Basilea: Birkhäuser Publishers - París: Fondation Le Corbusier, 1999. p. 33), 12 (Le Corbusier: Dibujo original del autor. FLC 31197. Fundación Le Corbusier. París, 1960), 13 (Le Corbusier: Dibujo original del autor. FLC 11644. Fundación Le Corbusier. París, 1963); página 60, 14 (Le Corbusier: Dibujo original del autor. FLC 28450. Fundación Le Corbusier. París, 1963), 15 (Le Corbusier: Dibujo original del autor. FLC 28460. Fundación Le Corbusier. París, 1963), 16 (Le Corbusier: A propósito del urbanismo. Barcelona: Editorial Poseidón, 1980. p. 144); página 63, 1 (From the archive of The Metropolitan Museum of Art, New York); página 64,2 (Courtesy of the digital archive of architectural images archINFORM), 3 y página 66, 4 (Wolfe, Ross: The Charnel-House. [en línea] New York. Disponible en www.thecharnelhouse.org); página 68, 5 (From the archive of the DEUTSCHES ARCHITEKTURMUSEUM), 6 (composed image, using different PROUNS of Lissintzky from www.wikipaintings.org); página 70, 7 (Composed image, using two drawing from the digital archive of architectural images archINFORM), 8 (From the permanent Collection of the Museo Nacional Centro de Arte Reina Sofía); página 74, 9 (Render of the project CAl Periféricos of the Empresa de Desarrollo Urbano de Medellín, EDU); página 78, 1 (El Croquis n.53, OMA/Rem Koolhaas, 1987-1993. Madrid: editorial El croquis, 1992, p. 167), 2 (Faucherau, Serge: Malévich, Barcelona: Ediciones Polígrafa, 1992, p. 143, figura 37), 3 (Aureli, Pier Vittorio: The Possibility of an absolute architecture. Cambridge: The MIT Press, 2011, p. 179); página 81, 4 (Gargiani, Roberto: Rem Koolhaas / OMA, the Construction of Maravilles. Lausanne: EPFL Press, 2008, p. 26 ), 5 (El Croquis n.53, OMA/Rem Koolhaas, 19871993. Madrid: editorial El croquis 1992, p. 169); página 82, 6 (El Croquis n.53, OMA/Rem Koolhaas, 1987-1993. Madrid: editorial El croquis 1992, p. 178), 7 (El Croquis n.53, OMA/Rem Koolhaas, 1987-1993. Madrid: editorial El croquis 1992, p. 173), 8 (El Croquis n.53, OMA/Rem Koolhaas, 1987-1993. Madrid: editorial El croquis 1992, p. 85), 9 (Aureli, Pier Vittorio: The Possibility of an absolute architecture. Cambridge: The MIT Press, 2011, p. 207); página 84, 10 (Venturi, Robert: Complexity and Contradicction in Architecture. New York: The Museum of Modern Art, 1966. p. 74), 11 ( AV Monografías 51-52, Enero-Abril 1995, p. 172), 12 (Arquitectura Viva n. 39, Noviembre-Diciembre 1994, p.43); página 86, 13 y 14 (OMA; Koolhaas, Rem; Mau, Bruce: SMLXL. Nueva York: The Monacelli Press, 1995. pp. 810-811); página 90, 1 (Courtesy of The MIT Press, from Grant Hildebrand, Designing for Industry: The Architecture of Albert Kahn. p.46), 2 (From the Collections of The Henry Ford); página 92, 3 (Nelson, George: Industrial Architecture of Albert Kahn, Inc. New York: Architectural Book Publishing Company, Inc, 1939, p.85. Foto: Hedrich-Blessing); página 93, 4 (Goldsmith, Myron: The Tall Building: the Effects of Scale, IIT, Chicago, 1953 (Tesis doctoral no publicada, revisada en. 1977 y 1986). [Versión consultada en: Goldmith, Myron y Werner Blaser (ed), Buildings and Concepts. New York: Rizzoli International Publications, 1987. pp.8-22.], p. 15), 5 (Goldsmith, M., op. cit. p. 17); página 94, 6 y página 95, 7 (Silvia Colmenares Vilata); página 96, 8 (Achilles, Rolf; Kevin Harrington and Charlotte Myhrum (ed.) Mies van der Rohe, architect as educator. Catalogue for the exhibition, 6 June through 12 July 1986 . Mies van der Rohe Centennial Project, IIT. Chicago: University of Chicago Press, 1986. pp.126 // Nelson, G. Op. cit. p. 38); página 97, 9 (Carter, Peter: Mies van der Rohe at Work. New York: Praeger, 1974. [Ed. Consultada: London: Phaidon, 1999, p. 8); página 98, 10 (Silvia Colmenares Vilata); página 99, 11 (Hvattum, Mari; Hermansen Cordua, Christian (eds.) Tracing Modernity: Manifestations of the Modern in Architecture and the City. London: Routledge, 2004. p. 126), 12 (Wesemael, Pieter van. Architecture of Instruction and Delight: A Socio-Historical Analysis of World Exhibitions As a Didactic Phenomenon (1798-1851-1970).Rotterdam: Uitgeverij 010, 2001. p. 170. (Manipulada)); página 100, 13 (Cedric Price fonds. Collection Centre Canadien d'Architecture/ Canadian Centre for Architecture, Montréal), 14 (Cedric Price fonds. Collection Centre Canadien d'Architecture/ Canadian Centre for Architecture, Montréal); página 101, 15 (Silvia Colmenares Vilata); página 106, 1, 2 y 3; página 108, 4 y 5 (Luis Palacios Labrador, 2011); página 110, 6 (Dibujo Luis Palacios Labrador, 2011. Fotografía: Strauven, Francis: Aldo Van Eyck. The Shape of Relativity. Amsterdam: Architectura \& Natura, 1998, pp. 375); página 113, 7 (Strauven, Francis: Aldo Van Eyck. The Shape of Relativity. Amsterdam: Architectura \& Natura, 1998, pp. 378), 8 (Strauven, Francis: Aldo Van Eyck. The Shape of Relativity. Amsterdam: Architectura \& Natura, 1998, p. 402); página 114, 9 (Risselada, Max; Van den Heuvel, Dirk: Team 10, 1953-81, in search of a Utopia of the present. Rotterdam: Nai Publishers, 2005, p. 117), 10 (Aldo van Eyck. The Web and the Labyrinth. En Lotus International. V.11. 1976); página 115, 11 (Sarkis, Hashim: Case: Le Corbusier's Venice Hospital and the Mat Building Revival. Munich: Prestel Verlag, 2001, p. 41); página 120, 1 (Antonio Millán Gómez, Marisol Jiménez, Julio Alan Latre y Víctor Díaz-Asensio García); página 123, 2 (Latre Cabrera, Julio Alan y Jiménez Rivera, Marisol); página 124, 3 (3.a. Busquets, Joan: El centro Histórico de Barcelona, un Pasado con futuro. Barcelona: Ajuntament de Barcelona, Foment Ciutat Vella; Universitat Politècnica de Catalunya, 2003; 3.b www.europeana.eu/portal/record/91932/CA529705B53B599FDD3C9A1ED7D5130497F5D000.html), 4 (Antonio Millán Gómez, Marisol Jiménez, Julio Alan Latre y Víctor Díaz-Asensio García); página 126, 5 (Latre Cabrera, Julio Alan y Jiménez Rivera, Marisol); página 128, 6 (llustre Municipalidad de Santiago); página 129, 7 (Archivo Visual de Santiago (www.archivovisual.cl) e llustre Municipalidad de Santiago / Santiago Centro. pp. 24-25); página 130, 8 (Lazo Mella, Felipe ; Millán Gómez, Antonio); página 131, 9 (Atlas del Proyecto de saneamiento del subsuelo de BarceIona. Lamina 3. Archivo Histórico de la Ciudad de Barcelona) 